\title{
Is supplemental oxygen necessary for intraoperative lung protective ventilation?
}

\author{
Shuji Okahara, Satoshi Suzuki and Hiroshi Morimatsu* \\ Department of Anaesthesiology and Resuscitology, Okayama University Hospital, Japan
}

The management of Postoperative Pulmonary Complications (PPCs) has recently received increasing research attention. PPCs, which can lead to serious morbidity, mortality and longer hospital stays, occur at a rate of approximately $5 \%$ in general surgical populations and may exceed $20 \%$ in high-risk patients [1]. Factors known to affect PPC development include patients' co-morbidity, surgical procedures and anaesthetic factors, particularly mechanical ventilation.

Intraoperative lung protective strategies, which comprise low tidal volume, Positive End-Expiratory Pressure (PEEP), and recruitment manoeuvres, have been reviewed. The results of two randomised controlled trials in patients undergoing abdominal surgery suggest that these approaches improve postoperative respiratory function as well as the incidence of PPCs [2,3]. Findings of two systematic reviews also revealed that low tidal volume with PEEP is associated with improved clinical pulmonary outcomes and reduced hospital stays in patients undergoing general surgery $[4,5]$. On the contrary, the PROVHILO study indicated that a high level of PEEP $\left(12 \mathrm{cmH}_{2} \mathrm{O}\right)$ and recruitment manoeuvres were comparable with a low level of PEEP $\left(\leq 2 \mathrm{cmH}_{2} \mathrm{O}\right)$ without recruitment manoeuvres for PPCs [6]. Despite mounting evidence of the benefits of low tidal volume and PEEP in lung protective strategies, optimal PEEP levels and the role of recruitment manoeuvres remain uncertain during general anaesthesia.

Supplemental oxygen is an essential component of ventilator management. However, it remains to be included in lung protective strategies. Reportedly, a high inspired oxygen fraction $\left(\mathrm{F}_{\mathrm{I}} \mathrm{O}_{2}\right)$ can be harmful and cause increased absorption atelectasis and lung injury. Worse clinical outcomes caused by high $\mathrm{F}_{\mathrm{I}} \mathrm{O}_{2}$ have been reported in critically ill adults, including patients with chronic obstructive pulmonary disease, myocardial infarction, cardiac arrest, stroke and traumatic brain injury [7-10]. Therefore, a conservative oxygenation strategy was proposed and evaluated in mechanically ventilated patients. It should be noted that conservative oxygen therapy has been associated with lower mortality, decreased incidence of atelectasis and earlier weaning from mandatory ventilation in the ICU $[11,12]$.

On the contrary, research on intraoperative conservative oxygen management is insufficient. A meta-analysis of randomised controlled trials showed that high $\mathrm{F}_{\mathrm{I}} \mathrm{O}_{2}$ did not increase the risk of atelectasis [13]. However, a recent registry report stated that high intraoperative $\mathrm{F}_{\mathrm{I}} \mathrm{O}_{2}$ was associated with major respiratory complications and 30-day mortality in a dose-dependent manner [14]. Moreover, a post hoc analysis of the PROXI trial suggested increased long-term mortality and higher incidence of myocardial infarction with higher $\mathrm{F}_{\mathrm{I}} \mathrm{O}_{2}[15,16]$.

Recently, we investigated the current practice of ventilator settings during One Lung Ventilation (OLV) and its association with PPCs [17]. We noted that a higher $\mathrm{F}_{\mathrm{I}} \mathrm{O}_{2}$ during OLV was applied in the majority of patients and was associated with the increased incidence of PPCs. Thus, growing evidence supports the requirement for randomised controlled trials for evaluating the safety and feasibility of conservative oxygen therapy during general anaesthesia.

Current oxygen management practices during general anaesthesia must be re-evaluated for preventing PPCs and protecting patients from unnecessary overdose treatment.

\section{References}

1. Canet J, Gallart L (2013) Predicting postoperative pulmonary complications in the general population. Curr Opin Anaesthesiol 26: 107-115. [Crossref]

2. Futier E, Constantin JM, Paugam-Burtz C, Pascal J, Eurin M, et al. (2013) A trial of intraoperative low-tidal-volume ventilation in abdominal surgery. $N$ Engl J Med 369: 428-437. [Crossref]

3. Severgnini P, Selmo G, Lanza C, Chiesa A, Frigerio A, et al. (2013) Protective mechanical ventilation during general anesthesia for open abdominal surgery improves postoperative pulmonary function. Anesthesiology 118: 1307-1321. [Crossref]

4. Serpa Neto A, Hemmes SN, Barbas CS, Beiderlinden M, Biehl M, et al. (2015) Protective versus Conventional Ventilation for Surgery: A Systematic Review and Individual Patient Data Meta-analysis. Anesthesiology 123: 66-78. [Crossref]

5. Yang D, Grant MC, Stone A, Wu CL, Wick EC (2016) A meta-analysis of intraoperative ventilation strategies to prevent pulmonary complications. Is low tidal volume alone sufficient to protect healthy lungs? Ann Surg 263: 881-887. [Crossref]

6. PROVE Network Investigators for the Clinical Trial Network of the European Society of Anaesthesiology, Hemmes SN, Gama de Abreu M, Pelosi P, Schultz MJ (2014) High versus low positive end-expiratory pressure during general anaesthesia for open abdominal surgery (PROVHILO trial): a multicentre randomised controlled trial. Lancet 384: 495-503. [Crossref]

7. Damiani E, Adrario E, Girardis M, Romano R, Pelaia P, et al. (2014) Arterial hyperoxia and mortality in critically ill patients: a systematic review and meta-analysis. Crit Care 18: 711. [Crossref]

8. Stub D, Smith K, Bernard S, Nehme Z, Stephenson M, et al. (2015) Air Versus Oxygen in ST-Segment-Elevation Myocardial Infarction. Circulation 131: 2143-2150. [Crossref]

9. Austin MA, Wills KE, Blizzard L, Walters EH, Wood-Baker R (2010) Effect of high flow oxygen on mortality in chronic obstructive pulmonary disease patients in prehospital setting: randomised controlled trial. BMJ 341: c5462. [Crossref]

10. Kilgannon JH, Jones AE, Parrillo JE, Dellinger RP, Milcarek B, et al. (2011) Relationship between supranormal oxygen tension and outcome after resuscitation from cardiac arrest. Circulation 123: 2717-2722. [Crossref]

11. Suzuki S, Eastwood GM, Goodwin MD, Noë GD, Smith PE, et al. (2015) Atelectasis and mechanical ventilation mode during conservative oxygen therapy: A before-andafter study. J Crit Care 30: 1232-1237. [Crossref]

${ }^{*}$ Correspondence to: Hiroshi Morimatsu, 2-5-1, Shiktacho, Kitaku, Okayama, 7008558 Japan, Tel: +81 86235 7324, Fax: +81 86235 6984, E-mail. morima-h@ md.okayama-u.ac.jp

Received: March 12, 2018; Accepted: March 23, 2018; Published: March 26, 2018 
12. Girardis M, Busani S, Damiani E, Donati A, Rinaldi L, et al. (2016) Effect of Conservative vs Conventional Oxygen Therapy on Mortality Among Patients in an Intensive Care Unit: The Oxygen-ICU Randomized Clinical Trial. JAMA 316: 15831589. [Crossref]

13. Hovaguimian F, Lysakowski C, Elia N, Tramèr MR (2013) Effect of intraoperative high inspired oxygen fraction on surgical site infection, postoperative nausea an vomiting, and pulmonary function: systematic review and meta-analysis of randomized controlled trials. Anesthesiology 119: 303-316. [Crossref]

14. Staehr-Rye AK, Meyhoff CS, Scheffenbichler FT, Vidal Melo MF, Gätke MR, et al. (2017) High intraoperative inspiratory oxygen fraction and risk of major respiratory complications. Br J Anaesth 119: 140-149. [Crossref]
15. Meyhoff CS, Jorgensen LN, Wetterslev J, Christensen KB, Rasmussen LS; PROXI Trial Group (2012) Increased long-term mortality after a high perioperative inspiratory oxygen fraction during abdominal surgery: follow-up of a randomized clinical trial. Anesth Analg 115: 849-854. [Crossref]

16. Fonnes S, Gögenur I, Søndergaard ES, Siersma VD, Jorgensen LN, et al. (2016) Perioperative hyperoxia - Long-term impact on cardiovascular complications after abdominal surgery, a post hoc analysis of the PROXI trial. Int J Cardiol 215: 238-243. [Crossref]

17. Okahara S, Shimizu K, Suzuki S, Ishii K, Morimatsu H (2018) Associations between intraoperative ventilator settings during one-lung ventilation and postoperative pulmonary complications: a prospective observational study. BMC Anesthesiol 18: 13. [Crossref]

Copyright: $(02018$ Okahara S. This is an open-access article distributed under the terms of the Creative Commons Attribution License, which permits unrestricted use, distribution, and reproduction in any medium, provided the original author and source are credited. 